\title{
Using Canopy Temperature Measurements to Evaluate Drought Tolerance of Potato Genotypes
}

\author{
Jeffrey C. Stark', Joseph J. Pavek ${ }^{2}$, and Ian R. McCann ${ }^{3}$ \\ University of Idaho Research and Extension Center, Aberdeen, ID 83210 \\ Additional index words. Solarium tuberosum, water stress, infrared thermometry, yield stability
}

\begin{abstract}
Field studies were conducted in 1986 and 1987 to evaluate the potential of using canopy temperature measurements to evaluate the relative drought tolerance of potato genotypes. In both years, 14 potato genotypes representing a relatively wide range of Solarium tuberosum L. germplasm were grown under well-watered [irrigation $\simeq 100 \%$ potential evapotranspiration (ET)] and stressed (irrigation $\simeq 40 \%$ to $50 \%$ potential ET) conditions. Irrigation differences were imposed with a line source irrigation system. Canopy temperatures of the 14 genotypes were measured between 0900 and $1430 \mathrm{HR}$ on 7 clear days during tuber bulking. A general linear relationship between canopy minus air temperature $(\Delta T)$ and air vapor pressure deficit (VPD) was determined for each year by regressing all $\Delta T$ data onto corresponding VPD values. The relative sensitivity of each genotype to changes in VPD was determined by regressing observed $\Delta \mathrm{T}$ values onto the estimated $\Delta \mathrm{T}$ from the general equation for that year. Genotypes with higher than average temperatures under well-watered conditions were generally less sensitive to changes in VPD than those with lower than average temperatures. Warmer genotypes under well-watered conditions were also generally less susceptible to drought than cooler genotypes. Thus, $\Delta \mathrm{T}$ measurements from well-watered plots can be effectively used to assess the relative drought tolerance of potato genotypes.
\end{abstract}

Canopy temperature measurements have been widely used in recent years to study the drought response of various crops (Blum et al., 1989; Chaudhuri et al., 1986; Hatfield et al., 1987; Singh and Kanemasu, 1983; Stark and Pavek, 1987). This approach is based upon the close, inverse relationship between leaf temperature and transpirational cooling (Jackson, 1982). Negative correlations between canopy temperature and water use have been reported for corn (Mtui et al., 1981) and sorghum (Chaudhuri and Kanemasu," 1982).

Blum et al. (1989) used canopy temperatures of droughtstressed wheat genotypes to characterize yield stability under various moisture conditions. They found a positive correlation between drought susceptibility and canopy temperature in stressed environments. Genotypes that suffered greater relative yield losses under drought stress tended to have warmer canopies at midday. Similar results have also been reported for potatoes (Stark and Pavek, 1987).

Results from several recent studies indicate that $\Delta \mathrm{T}$ from nonstressed environments can also be used to screen crop genotypes for drought susceptibility or yield stability. Singh and Kanemasu (1983) reported that the ratio of nonirrigated : irrigated yield of pearl millet genotypes was positively correlated with $\Delta \mathrm{T}$ from the irrigated environment. Hatfield et al. (1987) found that cotton strains that had higher canopy temperatures in irrigated plots produced greater biomass in dryland plots.

Chaudhuri et al. (1986) used relationships between $\Delta \mathrm{T}$ and corresponding air VPD measurements to characterize the response of sorghum and millet genotypes to changes in evaporative demand. They found that under well-watered conditions, warmer genotypes were generally less sensitive to changes in VPD than cooler genotypes. In addition, they found that the warmer genotypes were generally more productive under droughtstressed conditions.

Compared with most field crops, potatoes are considered to

\footnotetext{
Received for publication 4 June 1990. Univ. of Idaho Agricultural Experiment Station Paper no. 90735. The cost of publishing this paper was defrayed in part by the payment of page charges. Under postal regulations, this paper therefore must be hereby marked advertisement solely to indicate this fact.

Associate Professor, Dept. of Plant, Soil and Entomological Sciences. ${ }^{2}$ Research Geneticist, U.S. Dept. of Agriculture-Agricultural Research Service. ${ }^{3}$ Assistant Professor, Dept. of Agricultural Engineering.
}

be relatively drought-susceptible (Van Loon, 1981). Potato cultivars developed in North America and Europe are generally best adapted to cool, temperate zones. However, there currently is considerable interest in developing potato cultivars that will perform well in areas with hot, dry climates (Levy, 1986a, 1986b; Martin and Miller, 1983).

This study was conducted to determine whether $\Delta \mathrm{T}$ and VPD data from well-watered potatoes can be used to characterize the relative drought susceptibility of potato genotypes.

\section{Materials and Methods}

Fourteen potato genotypes were grown in 1986 and 1987 at the Aberdeen Research and Extension Center, Aberdeen, Idaho, under well-watered (irrigation $=100 \%$ potential ET) and stressed (irrigation $\approx 40 \%$ to $50 \%$ potential ET) conditions. The 14 genotypes represent a relatively wide range of $S$. tuberosum germplasm. Maximum vine size and leaf area for these 14 genotypes were fairly similar, with the exception of 'Frontier Russet' and 'Nooksack', which produced somewhat smaller vines. The experiments were conducted on a Delco silt loam (coarse-loamy, mixed, mesic Xerollic Calciorthid). All plots received a preplant application $\left(\mathrm{kg} \cdot \mathrm{ha}^{-1}\right) 200 \mathrm{~N}, 80 \mathrm{P}$, and $80 \mathrm{Kin} 1986$ and 1987.

A line-source sprinkler system (Hanks et al., 1976) was used to apply different amounts of water to $8 \times 12$-m plots of each genotype. Plots were arranged in a randomized complete-block design with six replications (three on each side of the line source). Potato rows were planted with a $0.91-\mathrm{m}$ row spacing and were oriented parallel to the line source so that row positions could be associated with specific irrigation environments. Rows designated as well-watered and stressed environments were located 1.4 and $10 \mathrm{~m}$ from the line source, respectively. Evapotranspiration was estimated from changes in soil water content in the well-watered plots. Gravimetric soil water content for the $\mathrm{O}$ to $60-\mathrm{cm}$ depth was determined at 2- to 3-day intervals throughout the growing season. Available soil water content in the wellwatered plots was consistently maintained above $65 \%$. Stressed rows received a total of 212 and $193 \mathrm{~mm}$ of irrigation + pre-

Abbreviations: DSI, drought susceptibility index; ET, evapotranspiration; AT, canopy - air temperature; VPD, vapor pressure deficit. 
cipitation in 1986 and 1987, respectively, while the well-watered rows received 464 and $470 \mathrm{~mm}$, respectively.

Canopy temperatures of the 14 genotypes were measured in the well-watered rows between 0900 and $1430 \mathrm{HR}$ on 7 clear days each year during tuber bulking. Canopy temperature was measured with a hand-held infrared thermometer (Teletemp Model AG-42, Fullerton, Calif.) calibrated regularly with a blackbody source to within $\pm 0.3 \mathrm{C}$. The instrument was held so as to view the crop at an angle of $30^{\circ}$ from the horizontal at right angles to the rows at a distance of $2.0 \mathrm{~m}$ from the sample row. This procedure was followed to minimize the influence of soil exposure. Each canopy temperature measurement was the average of six readings (three from each side of the row). Air temperature and VPD were determined concurrently with each set of six canopy temperature measurements using an aspirated psychrometer held $\approx 1 \mathrm{~m}$ over the crop canopy. Each set of measurements took $\approx 2$ min to complete and individual readings usually were within $\pm 0.2 \mathrm{C}$. Air temperatures during the sampling periods ranged from 18.3 to $33.4 \mathrm{C}$, while VPD ranged from $1.22 \mathrm{kPa}$ to $4.68 \mathrm{kPa}$. $\Delta \mathrm{T}$ typically was -1.0 to $-2.5 \mathrm{C}$ during the midmorning hours and increased to -4.0 to $-6.5 \mathrm{C}$ during the midafternoon. Wind speeds during the measurement periods were negligible $(<2 \mathrm{~m} \cdot \mathrm{s} 1)$.

A general linear relationship between $\Delta \mathrm{T}$ and VPD was determined for each year by regressing all AT data for each of the 14 genotypes on to corresponding VPD values in kilopascals. The general equation for all genotypes was $\Delta \mathrm{T}=0.36-1.41$ VPD $\left(r^{2}=0.70\right)$ in 1986 ; and $\Delta \mathrm{T}=0.56-1.76 \mathrm{VPD}$ $\left(r^{2}=0.83\right)$ in 1987. The relative sensitivity of each genotype to changes in VPD was determined by regressing observed $\Delta \mathrm{T}$ values onto the estimated $\triangle T(\bar{T})$, determined from the general equation for all genotypes for the corresponding VPD value. Genotypes having slopes (represented by $\Delta \mathrm{T} / \Delta \mathrm{T}$ ) $>1.0$ or $<1.0$ are interpreted as having greater or lesser sensitivity to changes in VPD compared to the average response for all genotypes (Chaudhuri et al., 1986). Examples of two genotypes having above or below average sensitivities to changes in VPD are presented in Fig. 1.

The single-row plots were mechanically harvested on 3 Oct. 1986 and 22 Sept. 1987. A drought susceptibility index (DSI) was subsequently determined for each genotype using the relationship presented by Fischer and Maurer (1978), DSI =

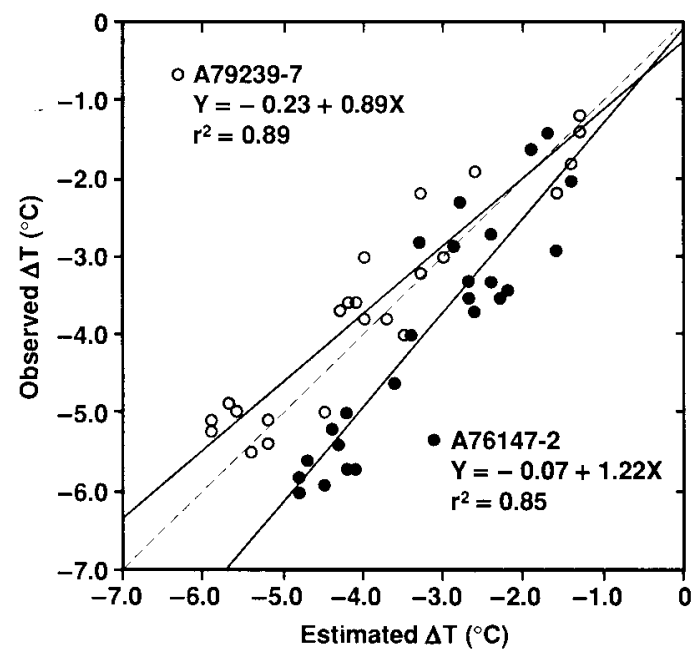

Fig. 1. Linear regressions of observed $\Delta \mathrm{T}$ onto estimated $\Delta \mathrm{T}$ at a given VPD for two potato genotypes in 1986. The dashed line indicates the 1:1 relationship for all 14 genotypes.
$\left(1-\mathrm{Y}_{\mathrm{d}} / \mathrm{Y}_{\mathrm{w}}\right) /\left(1-\mathrm{Y}_{\mathrm{d}} / \mathrm{Y}_{\mathrm{w}}\right)$ where $\mathrm{Y}_{\mathrm{d}}=$ fresh tuber yield under drought, $Y_{w}=$ fresh tuber yield under full irrigation, $Y_{d}=$ mean $\mathrm{Y}_{\mathrm{d}}$ for all genotypes, and $\mathrm{Y}_{\mathrm{w}}=$ mean $\mathrm{Y}_{\mathrm{w}}$ for all genotypes. This index provides a measure of relative drought tolerance based on minimization of yield loss under drought. Values $>1.0$ indicate greater than average drought susceptibility while values $<1.0$ indicate 'greater than average drought resistance.

\section{Results}

Drought susceptibility index values ranged from 0.86 to 1.16 in 1986 and from 0.88 to 1.08 in 1987 (Table 1). The results for 1986 and 1987 indicate that 'Russet Burbank', 'Red Pontiac', NDA1725-1, and A76147-2 are relatively drought susceptible (DSI > 1.0), while A79368-2, 'Monona', A79239-7, DTO-28, A7411-2, and 'Nooksack' are relatively drought resistant $(\mathrm{DSI}<1.0)$.

Mean AT values for the 14 potato genotypes ranged from -2.87 to $-4.21 \mathrm{C}$ in 1986 and from -2.93 to $-4.12 \mathrm{C}$ in 1987. The mean $\Delta \mathrm{T}$ for all genotypes was -3.52 and $-3.46 \mathrm{C}$ in 1986 and 1987, respectively. Mean $\Delta \mathrm{T}$ values for the 14 genotypes were linearly related to slopes from regressions of $\triangle \mathrm{T}$ on $\triangle \mathrm{T}$ in both 1986 and 1987 (Fig. 2). Genotypes with higher than average temperatures were generally less sensitive to changes in VPD than genotypes with lower than average temperatures. 'Red Pontiac ', 'Frontier Russet', NDA1725-1 and A76147-2 consistently exhibited above average sensitivity to changes in VPD (slopes > 1.0), while 'Lemhi Russet', A793682, 'Monona', A79239-7, DTO-28, and A7411-2 were relatively insensitive to VPD (slopes $<, 1.0$ ).

Mean $\triangle T$ and slopes of $\Delta T$ on $\Delta T(\Delta T / \widehat{T T})$ were not significantly correlated with stressed yield or well-watered yield (Table 2). However, mean $\Delta \mathrm{T}$ was negatively correlated with DSI in 1986 and 1987 , and $\Delta \mathrm{T} / \Delta \mathrm{T}$ was negatively correlated with DSI in 1987.

The relationship between mean $\Delta \mathrm{T}$ and DSI was linear for both years of the study (Fig. 3). Drought susceptibility of the different genotypes decreased as $\Delta \mathrm{T}$ increased. 'Red Pontiac', 'Frontier Russet', NDA1725-1, and A76147-2 consistently had lower than average canopy temperatures, while A79368-2, 'Monona', A79239-7, and A741 1-2 were consistently warmer than average. With the exception of 'Frontier Russet', the yield responses of these two groups consistently fell within the drought susceptible and drought tolerant categories, respectively. The other six genotypes exhibited greater variability in the relationship between mean $\Delta \mathrm{T}$ and DSI.

\section{Discussion}

Results of this study show that canopy temperature measurements from well-watered plots can provide an indication of relative drought susceptibility for different potato genotypes. However, genotypes with canopy temperatures that were well above or below average were easier to characterize than those with intermediate temperatures. For example, the relatively high drought susceptibility of 'Red Pontiac', NDA1725-1, and A761472 could be readily distinguished by comparing their relatively low temperatures with those of the other genotypes. At the other extreme, the comparatively high canopy temperatures of 'Monona' and A79368-2 gave a clear indication of their high degree of drought resistance. The drought responses of genotypes with intermediate temperatures were more variable.

Warmer potato genotypes were also less sensitive to changes in VPD than cooler genotypes. However, correlations between 
Table 1. Yield of 14 potato genotypes under stressed $\left(\mathrm{Y}_{\mathrm{d}}\right)$ and well-watered $\left(\mathrm{Y}_{\mathrm{w}}\right)$ conditions and corresponding DSI and mean $\Delta \mathrm{T}$ values in 1986 and 1987.

\begin{tabular}{|c|c|c|c|c|c|c|c|c|}
\hline \multirow[b]{3}{*}{ Genotype } & \multicolumn{8}{|c|}{ Yield, $\left(\mathrm{t} \cdot \mathrm{ha}^{-1}\right)}$, \\
\hline & \multicolumn{4}{|c|}{1986} & \multicolumn{4}{|c|}{1987} \\
\hline & $Y_{d}$ & $\mathrm{Y}_{\mathrm{w}}$ & $\mathrm{DSI}^{\mathrm{z}}$ & $\triangle \mathrm{T}$ & $Y_{d}$ & $Y_{w}$ & DSI & $\triangle \mathrm{T}$ \\
\hline 1. Russet Burbank & 15.8 & 37.1 & .1 .16 & -3.83 & 16.1 & 33.9 & 1.02 & -3.25 \\
\hline 2. Lemhi Russet & 22.1 & 46.6 & 1.06 & -3.45 & 18.5 & 37.5 & 0.98 & -3.35 \\
\hline 3. Frontier Russet & 17.6 & 32.4 & 0.94 & -3.68 & 15.3 & 32.8 & 1.04 & -4.12 \\
\hline 4. A79368-2 & 22.4 & 39.8 & 0.89 & -2.98 & 15.8 & 29.5 & 0.90 & -3.00 \\
\hline 5. Monona & 21.6 & 37.1 & 0.86 & -2.87 & 15.9 & 29.0 & 0.88 & -2.93 \\
\hline 6. Kennebec & 22.2 & 47.0 & 1.07 & -3.59 & 22.4 & 42.7 & 0.94 & -3.26 \\
\hline 7. A79239-7 & 17.7 & 34.5 & 0.98 & -3.32 & 16.0 & 32.5 & 0.99 & -3.24 \\
\hline 8. DTO-28 & 22.3 & 41.8 & 0.94 & -3.38 & 18.7 & 35.3 & 0.92 & -3.53 \\
\hline 9. Red Pontiac & 22.3 & 46.5 & 1.06 & -3.93 & 20.3 & 42.8 & 1.05 & -3.85 \\
\hline 10. NDA1725-1 & 23.2 & 51.5 & 1.13 & -4.21 & 19.1 & 42.3 & 1.08 & -4.06 \\
\hline 11. A76147-2 & 22.8 & 46.8 & 1.05 & -3.88 & 20.7 & 43.5 & 1.02 & -3.59 \\
\hline 12. Bintje & 18.5 & 35.9 & 0.99 & -3.41 & 15.5 & 33.2 & 1.04 & -3.62 \\
\hline 13. $A 7411-2$ & 21.4 & 37.4 & 0.88 & -3.30 & 16.1 & 32.3 & 0.97 & -3.05 \\
\hline 14. Nooksack & 19.0 & 33.3 & 0.87 & -3.42 & 16.6 & 32.7 & 0.97 & -3.60 \\
\hline Mean & 20.7 & 40.5 & & -3.52 & 17.6 & 35.7 & & -3.46 \\
\hline $\mathrm{LSD}_{0.05}$ & 4.9 & 3.5 & 0.08 & & 3.8 & 3.1 & 0.05 & \\
\hline
\end{tabular}

${ }^{2} \mathrm{DSI}=\left(1-\mathrm{Y}_{\mathrm{d}} / \mathrm{Y}_{\mathrm{w}}\right) /\left(1-\mathrm{Y}_{\mathrm{d}} \mathrm{Y}_{\mathrm{w}}\right.$.
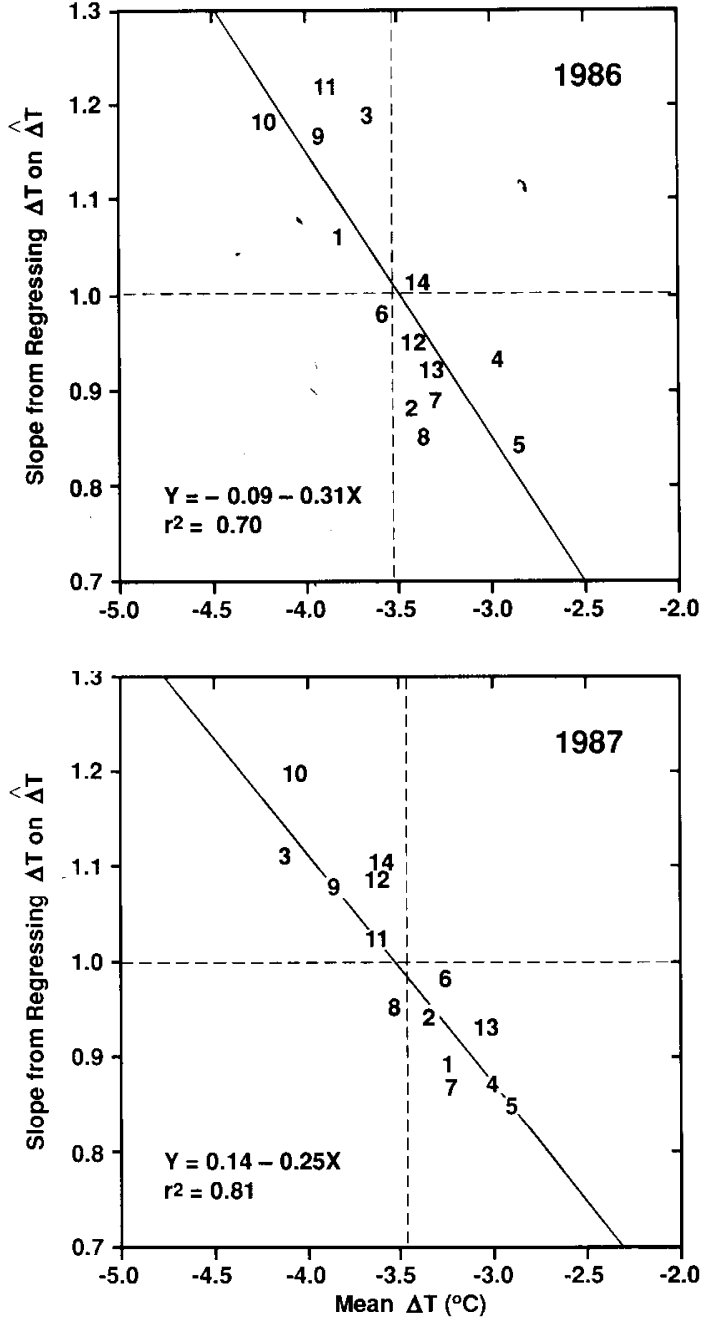

Fig. 2. Relationships between mean $\Delta \mathrm{T}$ and the slope from regressing $\Delta \mathrm{T}$ on $\Delta \mathrm{T}$ for 14 potato genotypes grown in 1986 (top) and 1987 (bottom). Numerical designations refer to the 14 genotypes as presented in Table 1.
Table 2. Simple correlations of stressed yield, well-watered yield, and DSI values with mean $\Delta \mathrm{T}$ values and slopes of regressions of $\triangle \mathrm{T}^{\mathrm{z}}$ on $\widehat{\triangle \mathrm{T}^{\mathrm{y}}}(\triangle \mathrm{T} / \widehat{\triangle \mathrm{T}})$.

\begin{tabular}{|c|c|c|c|c|}
\hline \multirow[b]{2}{*}{ Yield variable } & \multicolumn{2}{|c|}{1986} & \multicolumn{2}{|c|}{1987} \\
\hline & $\triangle \mathrm{T}$ & $\widehat{\triangle \mathrm{T}} / \widehat{\triangle \mathrm{T}}$ & $\Delta \mathrm{T}$ & $\triangle \mathrm{T} / \widehat{\Delta \mathrm{T}}$ \\
\hline Stressed yield & -0.02 & -0.05 & -0.20 & 0.24 \\
\hline Well-watered yield & -0.53 & 0.30 & -0.47 & 0.49 \\
\hline DSI & $-0.78^{* *}$ & 0.42 & $-0.73^{* *}$ & $-0.66^{* *}$ \\
\hline
\end{tabular}

$\mathrm{r} \mathrm{T}=$ canopy - air temperature.

$\mathrm{y} \triangle \mathrm{T}=$ estimated $\Delta \mathrm{T}$ from the general equation for all genotypes at a given VPD.

**Significant at $P=0.01$.

VPD sensitivity $(\triangle T / \widehat{\triangle T})$ and DSI were not as high as those between mean $\Delta \mathrm{T}$ and DSI. Therefore, the more straightforward approach of measuring $\Delta \mathrm{T}$ in well-watered plots appears to be a more effective means of assessing potato drought susceptibility than comparing $\Delta \mathrm{T}$ vs. VPD relationships.

The close relationship between $\Delta \mathrm{T}$ and DSI is consistent with the results of Hatfield et al. (1987) and Chaudhuri et al. (1986) who found that cotton, sorghum, and millet genotypes that had the warmest canopies under well-watered conditions generally produced the greatest biomass or yield under drought-stressed conditions. Hatfield et al. (1987) proposed that genotypes with high water-conserving ability will transpire less under optimal soil water conditions, thereby reducing transpirational cooling and increasing canopy temperature. The resulting lower crop water use should allow these genotypes to conserve more water for use during periods of drought.

Some investigators have used canopy temperatures from drought-stressed plots to assess genotypic response to drought (Blum et al., 1989; Stark and Pavek, 1987). In these studies, the most drought-resistant genotypes usually had the lowest canopy temperatures during periods of drought, apparently due to a greater ability to conserve or extract soil water.

There are, however, several advantages in using $\Delta \mathrm{T}$ data from nonstressed environments to characterize genotypic response to drought. From a management standpoint, it is much easier to standardize soil water levels under irrigated conditions 

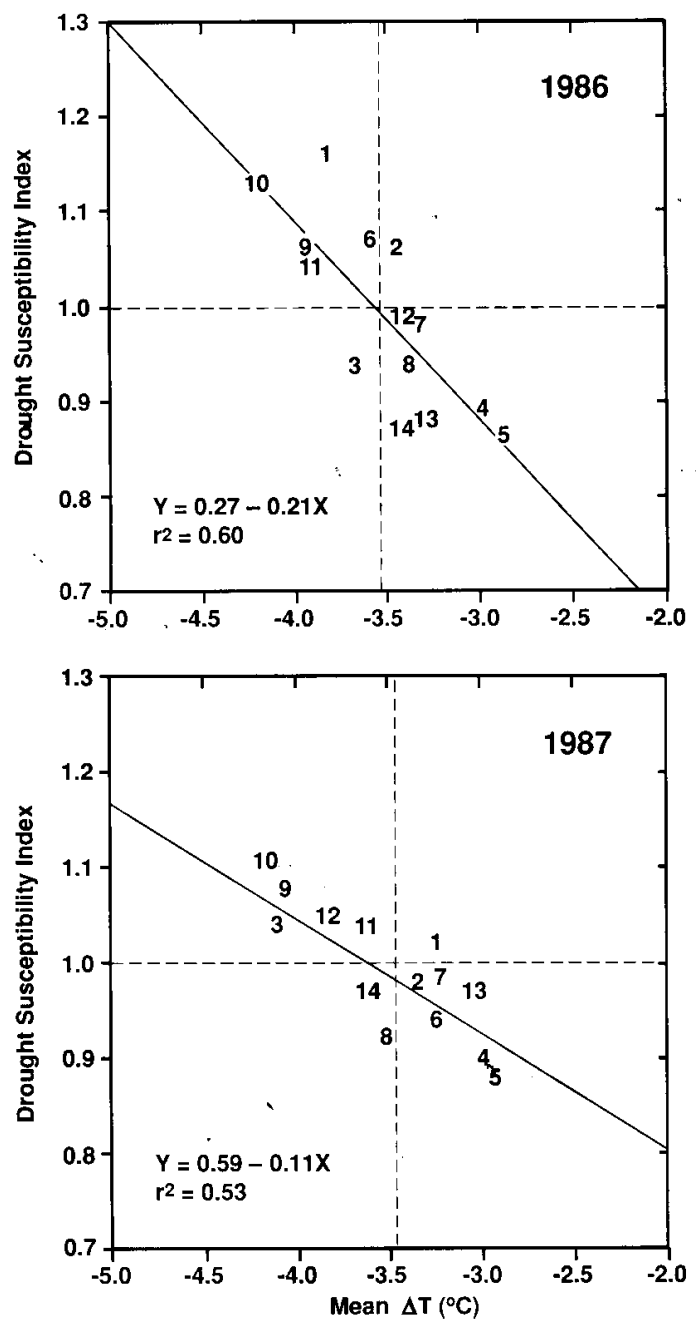

Fig. 3. Relationship between mean $\Delta \mathrm{T}$ and the drought susceptibility index for 14 potato genotypes grown in 1986 (top) and 1987 (bottom). Numerical designations refer to the 14 genotypes as presented in Table 1.

than under nonirrigated conditions. As soil water deficits increase, variability in soil texture and water-holding capacity will become an increasingly important source of variation that may mask genotypic differences. Differences in $\Delta \mathrm{T}$ among genotypes also tend to narrow with increasing water stress, making it more difficult to use this variable' to screen for drought resistance (Singh and Kanemasu, 1983). Furthermore, data can be collected from existing irrigated breeding plots, thereby avoiding the establishment of a parallel set of nonirrigated plots or the use of rain shelters.

It should be noted that the index used in this study to describe drought susceptibility is based on differences in fresh tuber weight and does not reflect differences in tuber quality. The quality and marketability of certain cultivars are often greatly affected by the timing and duration of water stress (Lynch and Tai, 1989; Miller and Martin, 1987). Consequently, additional research is needed to evaluate relationships between canopy temperature and tuber quality characteristics.

\section{Literature Cited}

Blum, A., L. Shipiler, G. Golan, and J. Mayer. 1989. Yield stability and canopy temperature of wheat genotypes under drought stress. Field Crops Res. 22:289-296.

Chaudhuri, U. N., M.L. Deaton, E.T. Kanemasu, G.W. Wall, V. Marcarian, and A.K. Dobrenz. 1986. A procedure to select droughttolerant sorghum and millet genotypes using canopy temperature and vapor pressure deficit. Agron. J. 78:490494.

Chaudhuri, U.N. and E.T. Kanemasu. 1982. Effect of water gradient on sorghum growth, water relations and yield. Can. J. Plant Sci. 62:599-607.

Fischer, R.A. and R. Mauer. 1978. Drought resistance in spring wheat cultivars. I. Grain yield response. Austral. J. Agr. Res. 29:897-907.

Hanks, R. J., J. Keller, V.P. Rasmussen, and G.D. Wilson. 1976. Line source sprinkler for continuous variable irrigation - crop production studies. Soil Sci. Soc. Amer. J. 40:426-129.

Hatfield, J. L., J.E. Quisenberry, and R.E. Dilbeck. 1987. Use of canopy temperatures to identify water conservation in cotton germplasm. Crop Sci. 27:269-273.

Jackson, R.D. 1982. Canopy temperature and crop water stress, p. $43-$ 85. In: D.E. Hillel (cd.). Advances in irrigation Academic, New York.

Levy, D. 1986a. Genotypic variation in the response of potatoes (Solanum tuberosum L.) to high ambient temperatures and water deficit. Field Crops Res. 15:85-96.

Levy, D. 1986b. Tuber yield and tuber quality of several potato cultivars as affected by seasonal high temperatures and by water deficit in a semi-arid environment. Potato Res. 29:95-107.

Lynch, D.R. and G.C.C. Tai. 1989. Yield and yield component response of eight potato genotypes to water stress. Crop Sci. 29:12071211.

Martin, W.M. and D.E. Miller. 1983. Variations in responses of potato germplasm to deficit irrigation as affected by soil texture. Amer. Potato J. 60:671-683.

Miller, D.E. and M.W. Martin. 1987. Effect of declining or interrupted irrigation on yield and quality of three potato cultivars grown on a sandy soil. Amer. Potato J. 64: 109-1 17.

Mtui, T.A., E.T. Kanemasu, and C. Wassom. 1981. Canopy temperatures, water use, and water use efficiency of corn genotypes. Agron. J. 73:639-643.

Singh, P. and E.T. Kanemasu. 1983. Leaf and canopy temperatures of pearl millet genotypes under irrigated and nonirrigated conditions. Agron. J. 75:497-501.

Stark, J.C. and J.J. Pavek. 1987. Selection of drought tolerant potato clones using foliage temperature measurements. 10th Triennial Conf. Eur. Assn. Potato Res. p. 26-27. (Abstr.)

Van Loon, C.D. 1981. The effect of water stress on potato growth, development and yield. Amer. Potato J. 58:51-69. 